\title{
1 Effects of Limonene on the PAHs mutagenicity risk in Roasted Fish Skin
}

2 Yu-Wei Chen ${ }^{1}$, Ping-Hsiu Huang ${ }^{2}$, Yung-Hsiang Tsai ${ }^{1}$, Chii-Ming Jiang ${ }^{3}$, Chih-Yao

$3 \mathrm{Hou}^{1 *}$

4

5 Yu-Wei Chen M.D.

$6{ }^{1}$ Department of Seafood Science, National Kaohsiung University of Science and

7 Technology, Kaohsiung, Taiwan, ROC

8 Naosa720928@gmail.com

9

10 Ping-Hsiu, Huang Ph. D.

$11{ }^{2}$ College of Food Science and Technology, Hainan University, Haikou, China

12 hugh0530@gmail.com

13

14 Yung-Hsiang Tsai Ph. D.

$15{ }^{3}$ Department of Seafood Science, National Kaohsiung University of Science and

16 Technology, Kaohsiung, Taiwan, ROC

17 yht@mail.nkmu.edu.tw 
19 Chii-Ming Jiang $\mathrm{Ph}$. D.

$20{ }^{3}$ Department of food science and technology National Taitung Jr. College, Taitung,

21 Taiwan, ROC

22 cmjiangkimo@yahoo.com.tw

23

24 Chih-Yao, Hou Ph. D.

$25{ }^{1}$ Department of Seafood Science, National Kaohsiung University of Science and

26 Technology, Kaohsiung, Taiwan, ROC

27 chihyaohou@gmail.com

$28+88673617141 * 23607$

29

30

31

32 ABSTRACT

33 Traditional edible barbecue products use with lemon juice not only make the

34 barbecue more delicious but also reduce the risk of PAHs in the barbecue products. One

35 of the major economics crops in Taiwan, the waste from citrus fruits was very tremendous

36 mass. However, the peelings of citrus fruits are rich in essential oil, especially, the 
37 limonene is the major. Whether the anti-carcinogenesis activities of terpene, such as

38 limonene, in citrus fruits essential oil extraction. This study to demonstrate the PAHs

39 content in fish skin increased markedly after being roasted at $210^{\circ} \mathrm{C}$ for 20 minutes and

40 greater mutagenicity risk of roasted fish skin was observed by Ame's test. The reduction

41 of mutagenicity risk of roasted fish skin, which the antimutagenic abilities of substances

42 in descending order were limonene $>$ cold pressure oil $>$ lemon $>$ grapefruit. The

43 antimutagenicity rate and ability of the three extracts were limonene: $18-23 \%$; cold-

44 pressed lemon oil: 18-22\%; and steam distilled lemon essential oil: 8-16\%. The obvious

45 anti- mutagenicity effects against the PAHs mutagenicity of roasted fish skins can be

46 found in citrus fruits essential oil extraction.

47 Keywords: Roasted Fish Skin, PAHs mutagenicity risk, Limonene

49 1. Introduction

50 Citrus is one of the most abundant agriculture crops worldwide. With a global

51 production of 4,200,000 metric tonnes, lemon (Citrus limon (L.)) is the third most

52 important cultivated citrus species after orange and mandarin. Countries with the most

53 important lemon productions for processing are Argentina (1,000,000 tonnes), Italy

54 (304,000 tonnes), Spain (300,000 tonnes), USA (230,000 tonnes), and Mexico (296,000 
55 tonnes). Of the 2,130,000 tonnes of lemons processed globally in 2007, peel waste made

56 up 57\% ( 1,200,000 tonnes) [1]. Citrus peels are rich in essential oils, which in various

57 plants exhibit antioxidant properties that can extend the shelf life in foods by lowering

58 lipid oxidation [2]. High-purity limonene, a major component of lemon essential oil found

59 in the peels, can be used as fragrance, flavour, insecticide, or renewable solvent for

60 coating or replacing aromatic and mineral oils [3]. Researchers worldwide are

61 investigating this substance as a method to protect food from bacterial growth without the

62 need for harmful chemicals [4].

63

64 Polycyclic aromatic hydrocarbons (PAHs) are organic toxins consisting of two or

65 more aromatic rings fused in linear, angular, or clustered arrangements. These compounds

66 do not undergo self-degradation easily in nature owing to their stable chemical structures

67 [5]. Some PAHs such as acenaphthene anthracene, phenanthrene, fluorene, fluoranthene,

68 pyrene, benzo[a]pyrene are included in the list of priority pollutants by the United States

69 Environmental Protection Agency [5]. In 1976, there are at least 30 PAHs that are

70 recognised internationally to be carcinogens, which is the largest group of known

71 carcinogens in the world currently.

72 PAHs cause severe pollution in the biosphere due to its environmental dissemination 
73 and bioaccumulation characteristics. PAHs are mainly produced from incomplete

74 combustion of carbon-containing compounds or use of fossil fuels. Examples include the

75 combustion of plants that releases and spreads PAHs into nature; spillage of crude oil in

76 the petrochemical industry [5]; roasted meats, smoked fishes, and cured meats. The use

77 of baking, roasting, and other cooking techniques will generate more PAHs and increase

78 PAH content in foods [6-9]. Consumption of fish and roasted and smoked meats by

79 humans allow PAHs to enter the human body. In this study, tilapia skins were soaked in

80 limonene and lemon essential oil to examine their ability to prevent PAH-induced

81 mutagenicity induced by roasting.

82

83 2. Materials and methods

$84 \quad 2.1$ Materials

85 Lemons (C. limon) purchased from a supermarket in Kaohsiung city were washed

86 and wiped dry. Lemon skins were collected without disrupting the oil sacs and were

87 directly used for subsequent experiments.

88 Limonene, glucose-6-phosphate, $\beta$-Nicotine adenine dinucleotide phosphate, and

89 sodium ammonium hydrogen phosphate tetrahydrate were purchased from Fluka

90 Chemical Corp, US. Cold oil presses for lemon skins were provided by the fragrance 
91 company. Benzo [a]pyrenene was purchased from Supelco Inc., US. 4-Nitroquinoline-N-

92 oxide L-histidine, Sodium chloride and D-biotin were purchased from Sigma Inc., US.

93 Nutrient agar, nutrient broth, tryptic soy agar, tryptic soy broth, and Bacto agar were

94 purchased from Difco Inc., US. Magnesium sulfate heptahydrate, citric acid, $\mathrm{H}_{2} \mathrm{O}$,

95 dipotassium hydrogen phosphate, magnesium chloride anhydrous, potassium chloride,

96 sodium dihydrogenphosphate anhydrous, disodium hydrogenphosphate, and glucose

97 were purchased from Showa Inc., JP.

98

99

100

2.4. Methods

101

2.4 Extraction and analysis of essential oil from citrus peels

102

2.4.1.1 Steam distillation

103 $700 \mathrm{~g}$ of distilled water was added to $150 \mathrm{~g}$ of citrus peels for blending before being

104 placed in a three-neck round-bottom flask for steam distillation. After the distillate

105 separated into layers, the upper layer containing distilled essential oil was collected. This

106 oil was stored in the dark at $-20^{\circ} \mathrm{C}$ before gas chromatography-mass spectrometry

107 (GC/MS) was used to analyse the types and levels of compounds [10], [11]

108

109

2.4.1.2 Cold pressing of lemon essential oils 
111 removed, and the peels were pressed. Afterward, distilled water was used to flush the

112 pressed juice. The mixture was then centrifuged at $3000 \mathrm{rpm}$ for $10 \mathrm{~min}$. Cold pressed oil

113 was then collected from the upper layer.

114

$115 \quad 2.4 .2$ Analysis of citrus peel essential oil

116 The Agilent 6890 (Agilent technologies Inc., US) GC system used in this was

117 connected in tandem to an Agilent 5973N quadrupole mass selective detector (MSD). The

118 temperature of the ion source was $230^{\circ} \mathrm{C}$, and the quadrupole temperature was $150^{\circ} \mathrm{C}$. A

119 DB-1 separating column with a length of $60 \mathrm{~m}$ and inner diameter of $0.25 \mathrm{~mm}$ was used;

120 the injection port temperature was $150^{\circ} \mathrm{C}$. The initial temperature of the column was $40^{\circ} \mathrm{C}$

121 for $0 \mathrm{~min}$, which increased to $75^{\circ} \mathrm{C}$ at $35^{\circ} \mathrm{C} / \mathrm{min}$ before holding for $2 \mathrm{~min}$. This was

122 followed by an increase of $5^{\circ} \mathrm{C} / \mathrm{min}$ to $120^{\circ} \mathrm{C}$ and holding for $0 \mathrm{~min}$. Finally, the

123 temperature was increased at $15^{\circ} \mathrm{C} / \mathrm{min}$ to $210^{\circ} \mathrm{C}$ and was held at $2 \mathrm{~min}$. The carrier gas

124 used was helium, and the flow rate was $1 \mathrm{~mL} / \mathrm{min}$. The obtained MS data were aligned

125 with the Wiley7n Mass Spectral Library.

126

1272.5 Toxicity, mutagenic, and anti-mutagenic effects of limonene and citrus essential oil 


\subsubsection{S. typhimurium TA100 experiment strains}

131 Biotechnology was used to modify this genetically defective strain from that

132 growing in a histidine-deficient environment to a strain that requires histidine for growth.

133 Samples containing mutagenic substances will revert back to a histidine-independent

134 form. This experiment strain was obtained from Chung Shan Medical University.

\subsubsection{Toxicity testing}

137 This test examines whether the experimental samples exhibit toxicity towards bacteria in the presence or absence of metabolism by liver enzymes. Toxicity is present if

139 the colony count of the experimental group is $80 \%$ of that in the control group. The

140 experimental samples of limonene and citrus essential oil were diluted by $1 \%$ Tween into

141 different concentrations. The control group consisted of 1\% Tween. Hereafter, these

142 samples are referred to as "experimental Tween samples" and "Tween control group,"

143 respectively.

144 First, $0.1 \mathrm{~mL}$ of the Tween sample was added into $0.1 \mathrm{~mL}$ of phosphate buffer $(\mathrm{pH}$

145 7.4) before $0.1 \mathrm{~mL}$ of overnight bacterial culture was added. For the group without S9 
146 mixture, $0.5 \mathrm{~mL}$ of the phosphate buffer was added. For that with $\mathrm{S} 9$, this mixture was

147 added in place of the phosphate buffer. After mixing, the mixtures were precultured for

$14820 \mathrm{~min}$ at $37^{\circ} \mathrm{C}$. They were then diluted to $10^{2}-10^{3} \mathrm{CFU} / \mathrm{mL}$, and $1 \mathrm{~mL}$ of diluate was

149 mixed with a suitable volume of melted nutrient agar. The plates were grown in an

150 inverted position at $37^{\circ} \mathrm{C}$ for $48 \mathrm{~h}$ before the colony counts were enumerated.

151

152

\subsubsection{Mutagenicity experiments}

153

The method used to perform the mutagenicity test (Ames test) involved the pre-

154

incubation method as described by Maron and Ames [13]. This test examined whether

155 the experimental samples exhibited mutagenic effects towards bacteria in the presence or

156 absence of metabolism by liver enzymes. If the data of the experimental group were more

157 than twice that of the control group, the sample was mutagenic.

158

First, $0.1 \mathrm{~mL}$ of the experimental Tween sample was added to $0.1 \mathrm{~mL}$ of the

159 phosphate buffer before $0.1 \mathrm{~mL}$ of overnight bacterial culture was added. For the group

160 without $\mathrm{S} 9$ mixture, $0.5 \mathrm{~mL}$ of the phosphate buffer was added. For that with $\mathrm{S} 9$, this

161 mixture was added place of the phosphate buffer. After mixing, the mixtures were

162 precultured for $20 \mathrm{~min}$ at $37^{\circ} \mathrm{C}$. Then, $2 \mathrm{~mL}$ melted top agar containing $40 \%$ glucose and

$1630.5 \mathrm{mM}$ histidine/biotin solution was added. The plates were grown in an inverted position 
164 at $37^{\circ} \mathrm{C}$ for $48 \mathrm{~h}$ before the colony counts were enumerated [14].

165

$166 \quad$ 2.5.4 Antimutagenicity experiments

167

This experiment examines whether the experimental samples have antimutagenic

168 ability following the addition of standard mutagens that do or do not require liver enzyme

169 metabolism. The mutagen selected for the group without S9 mixture added was 4-

170 Nitroquinoline-N-oxide, which does not require metabolism by liver enzymes.

171 Benzo[a]pyrene, which requires liver enzyme metabolism, was used for the group with

$172 \mathrm{~S} 9$ mixture added. In both cases, $0.1 \mathrm{~mL}$ of overnight bacterial culture was added.

173 First, $0.1 \mathrm{~mL}$ of the experimental Tween sample was added into $0.1 \mathrm{~mL}$ of

174 commercial mutagens. For the group without S9 mixture, $0.5 \mathrm{~mL}$ the phosphate buffer

175 was added. For that with S9, this mixture was added in place of the phosphate buffer.

176 After mixing, the mixtures were precultured for 20 minutes at $37^{\circ} \mathrm{C}$ before $2 \mathrm{~mL}$ of melted

177 top agar containing $40 \%$ glucose and $0.5 \mathrm{mM}$ histidine/biotin solution was added. The

178 plates were grown in an inverted position at $37^{\circ} \mathrm{C}$ for 48 hours before the colony counts

179 were enumerated [15].

180 Antimutagenicity was calculated according to the following formula:

181 Inhibition $(\%)=[1-($ number of spontaneous revertants sample group/ control group) $] \times$ 
1842.6 Antimutagenicity of limonene and citrus essential oil on roasted fish skins

185 2.6.1 Extraction of roasted fish skins

186 $70 \mathrm{~g}$ of descaled tilapia skins $20 \mathrm{~cm}$ long $\times 8 \mathrm{~cm}$ wide was weighed and washed before being wiping dry (treated samples). Afterwards, the skins were placed in an oven 188 for $20 \mathrm{~min}$ of roasting at $210^{\circ} \mathrm{C}$. After the skins were crushed, three volumes of

189 dichloromethane were added for $1 \mathrm{~h}$ of extraction. The dichloromethane layer was 190 collected and concentrated under reduced pressure. The concentrate obtained was stored 191 in the dark at $-20^{\circ} \mathrm{C}$.

192

193 2.6.2 Toxicity of extracts from roasted fish skins This test examines whether the extracts from roasted fish skins exhibit toxicity

195 towards bacteria in the presence or absence of metabolism by liver enzymes. Toxicity is 196 present if the colony count of the experimental group is $80 \%$ of that in the control group.

197 Extracts from roasted fish skins were dissolved in dimethyl sulfoxide (DMSO). The control group contained DMSO alone; these are referred to as "experimental DMSO samples" and "DMSO control group," respectively. First, $0.1 \mathrm{~mL}$ of experimental DMSO 
200 samples was added to $0.1 \mathrm{~mL}$ of phosphate buffer $(\mathrm{pH} \mathrm{7.4)}$ and $0.1 \mathrm{~mL}$ of overnight

201 culture. The group without S9 mixture had $0.5 \mathrm{~mL}$ of the phosphate buffer added, whereas

202 the group with S9 had the S9 mixture added in place of the aforementioned $0.5 \mathrm{~mL}$

203 phosphate buffer. After mixing, the mixtures were precultured for $20 \mathrm{~min}$ at $37^{\circ} \mathrm{C}$. The

204 mixture was diluted to $10^{2}-10^{3} \mathrm{CFU} / \mathrm{mL}$, and $1 \mathrm{~mL}$ of diluate was mixed with a suitable

205 volume of melted nutrient agar. The plates were grown in an inverted position at $37^{\circ} \mathrm{C}$ for

$20648 \mathrm{~h}$ before the colony counts were enumerated [13-15].

207

208 2.6.3 Mutagenicity of extracts from roasted fish skins

209 This test examines whether the experimental samples exhibit mutagenic effects

210 towards bacteria in the presence or absence of metabolism by liver enzymes. If the data

211 of the experimental group is more than twice that of the control group, the sample is

212 mutagenic. First, $0.1 \mathrm{~mL}$ of DMSO experimental samples was added to $0.1 \mathrm{~mL}$ of

213 phosphate buffer ( $\mathrm{pH} 7.4)$ before $0.1 \mathrm{~mL}$ of overnight bacterial culture was added. The

214 group without S9 mixture had $0.5 \mathrm{~mL}$ of the phosphate buffer added, whereas the group

215 with S9 had the S9 mixture added in place of the aforementioned phosphate buffer. After

216 mixing, the mixtures were precultured for 20 min at $37^{\circ} \mathrm{C}$ before adding $2 \mathrm{~mL}$ of melted

217 TOP agar containing $40 \%$ glucose and $0.5 \mathrm{mM}$ histidine/biotin solution. The plates were 
218 grown in an inverted position at $37^{\circ} \mathrm{C}$ for $48 \mathrm{~h}$ before the colony counts were enumerated $219 \quad[14]$.

220

221 2.6.4 Antimutagenicity of limonene and citrus essential oil on extracts from roasted fish

222 skins

223

This experiment examines whether limonene and lemon essential oil, including cold

224 pressed oil and that from steam distillation, have antimutagenic ability when extracts are

225 added from roasted fish skin in the presence or absence of liver enzyme metabolism. First,

$2260.1 \mathrm{~mL}$ of experimental Tween samples was added to $0.1 \mathrm{~mL}$ of extracts from roasted fish

227 skins; the extracts were dissolved in DMSO as $50 \mu \mathrm{g} /$ plate and $200 \mu \mathrm{g} / \mathrm{plate}$. The group

228 without $\mathrm{S} 9$ mixture had $0.1 \mathrm{~mL}$ of overnight bacterial culture added before the addition

229 of $0.5 \mathrm{~mL}$ of phosphate buffer ( $\mathrm{pH} 7.4)$. For the group with $\mathrm{S} 9$, S9 mixture was added in

230 place of the aforementioned phosphate buffer. After mixing, the mixtures were

231 precultured for $20 \mathrm{~min}$ at $37{ }^{\circ} \mathrm{C}$ before adding $2 \mathrm{~mL}$ of melted TOP agar containing $40 \%$

232 glucose and $0.5 \mathrm{mM}$ histidine/biotin solution. The plates were grown in an inverted

233 position at $37^{\circ} \mathrm{C}$ for $48 \mathrm{~h}$ before the colony counts were enumerated [13-15]..

235 2.6.5 Evaluation of toxicity and mutagenicity of fish skin extracts regarding $S$. 
236

237

238

239

240

241

242 and three volumes of dichloromethane were added for $1 \mathrm{~h}$ of extraction. The

243 dichloromethane layer was collected and concentrated under reduced pressure. The

244 concentrate obtained was used for toxicity and mutagenicity evaluation following the

245 procedures in described in sections 2.6.2 and 2.6.3.

247 2.6.6 Evaluation of toxicity and mutagenicity of fish skin extracts regarding $S$.

248 typhimurium TA 100

$70 \mathrm{~g}$ of descaled Tilapia skins $20 \mathrm{~cm}$ long $\times 8 \mathrm{~cm}$ wide was weighed and washed

250

before being wiped dry. Afterwards, the skins were soaked in $15 \mathrm{~mL}$ of $10 \%$ limonene

251 and lemon essential oil, including cold pressed oil and that extracted from steam

252 distillation, until the oils were completely absorbed, about 10-15 min. The skins were

253 then placed in an oven for 20 min of roasting at $210^{\circ} \mathrm{C}$. Afterwards, the skins were crushed 
254 and, three volumes of dichloromethane were added for $1 \mathrm{~h}$ of extraction. The

255 dichloromethane layer was collected and concentrated under reduced pressure. The

256 concentrate obtained was used for toxicity and mutagenicity evaluation, following the

257 procedures described in sections 2.6.2 and 2.6.3.

$258 \quad 2.7$ Statistical analysis

259 Statistical analysis was conducted with one-way analysis of variance (ANOVA) with

260 an LSD post hoc test for multiple comparisons. Data are reported as the mean \pm standard

261 error of mean (SEM) with a $\mathrm{p}$ value less than 0.05 being considered statistically

262 significant. Analyses were performed using the Statistical Package for the Social Sciences

263 (SPSS) software (Chicago, IL, USA).

264 3. Results and discussion

2653.1 Identification of components in citrus essential oils

266

In total, 26 aromatic compounds were identified from the citrus essential oil obtained

267 by different extraction methods (Table 1). Terpenes had the highest levels, accounting for

26820 of the 26 aromatic compounds; the remaining compounds consisted of 4 types of

269 aldehydes and 2 types of esters. The limonene content in the four types of citrus essential

270 oils was $70-90 \%$, showing that limonene content in citrus essential oils is extremely high.

271 In addition, the lemon essential oils all contained $\beta$-Pipene and $\gamma$ - Terpinene regardless 
272 of whether cold pressing or steam distillation was used. Studies have shown that these

273 two compounds have antimicrobial and anti-cancer properties [16-20].

274

275

3.2. Toxicity, mutagenicity, and antimutagenicity tests

276

The method used to perform the mutagenicity test (Ames test) involved the pre-

277 incubation method as described by Maron and Ames [13]. In the Ames test, toxicity

testing is an extremely important step. The test sample must first undergo toxicity testing

279 so that the sample concentration used in subsequent experiments will not have toxic effects on the experimental bacterial strains. This is because if toxicity occurs when the sample concentration is not high, error in colony counts can occur in subsequent experiments [14]. Therefore, it is necessary to determine the concentration with no toxicity effects when conducting the Ames test [15]. While determining whether the sample concentrations have toxicity effects, we can monitor whether the colony counts of the test sample group are lower than $80 \%$ of the control group. If so, concentration is toxic to the experimental bacterial strain and is not suitable for subsequent experiments.

Table 2, shows that as the sample concentration increased, the bacterial counts exhibited a gradual decreasing trend regardless of whether liver enzymes were added. Toxicity occurs when the concentration of limonene is greater than $100 \mu \mathrm{g} / \mathrm{plate}$ and when the concentration of limonene, cold pressed oil, lemon essential oil, and the extract from roasted fish skins are greater than $200 \mu \mathrm{g} /$ plate. Therefore, this value was used as the maximum concentration for the four samples in subsequent experiments. However,

293 within this concentration range, the colony counts exhibited a significant increasing trend as the concentration of roasted fish skin extracts increased. This shows that animal tissues 
295 undergoing high-temperature roasting contain large amounts of toxic substances that could cause DNA mutations, which is similar to the document released by the World

297 Health Organization [5].

After identifying the concentration not causing toxicity, mutagenicity experiments were conducted to confirm that the test samples are safe and not mutagenic in order to avoid errors in colony counts and doubts about safety. Therefore, this test must be conducted if the sample is determined to be antimutagenic or edible so that antimutagenicity and safety can be accurately calculated in subsequent antimutagenicity experiments [21].

When determining whether the test sample is mutagenic, the colony counts of the test sample and control groups are compared. If the colony counts of the sample group are more than twice that of the control group, safety issues and mutagenicity are present for that concentration, which makes it unsuitable for subsequent experiments [22-23]. Table 2 shows that the colony count trends of the four test samples at various concentrations were comparable with the control group, regardless of whether liver enzymes were added. This shows that the concentrations of these samples are not mutagenic towards the bacterial strain used. The results showed that when 100 and 200 $\mu \mathrm{g} /$ plate concentrations of limonene and various citrus essential oils were used, respectively, no mutagenicity was present, and the safety of the samples was confirmed. Antimutagenicity analysis was conducted according to the confirmed sample concentrations in the two aforementioned experiments. The aims of this experiment were to examine whether these four samples can decrease mutagenicity caused by interaction

317 with mutagens and to calculate the antimutagenicity rate. Table 3 shows that as the concentrations of these four samples increased, the antimutagenicity rate against two 
319 standard mutagens, 4-Nitroquinoline-N-oxide and benzo[a]pyrene, both increased 320 regardless of whether liver enzymes were added. The antimutagenicity rate and ability of

321 these samples at their highest concentrations were limonene: $49-52 \%$; cold pressed lemon 322 oil: 45\%; steam distilled lemon essential oil: $342 \%$; and extract from roasted fish skins: $323286-551 \%$ Overall, the three citrus essential oils all have antimutagenic effects, which

324 were strongest in limonene and lemon essential oil. Therefore, subsequent studies were 325 conducted using limonene and lemon essential oil for toxicity, mutagenicity, and 326 antimutagenicity evaluation on extracts from roasted fish skins.

327

3283.4 Antimutagenicity of limonene and citrus essential oils on extracts from roasted fish

329 skins Antimutagenicity tests using the three citrus essential oils were conducted using a

331 high mutagenicity concentration. In this experiment, limonene, cold pressed lemon oil,

332 and steam distilled extracted lemon essential oil were used as experimental samples. Table

3333 shows the results. Under the maximum concentrations of these three samples, the

334 antimutagenicity rate and ability of these samples towards extracts from roasted fish skin

335 (200 $\mu \mathrm{g} /$ plate) were limonene: 18-23\%; cold pressed lemon oil: 18-22\%; and steam

336 distilled extracted lemon essential oil: $8-16 \%$. The antimutagenicity rate exhibited

337 significant increases only under high doses of samples, which is likely attributed to the overly high concentration of the fish extracts. Therefore, a lower concentration of 
339 mutagenic fish skin extract $(50 \mu \mathrm{g} /$ plate $)$ was used for subsequent identical experiments.

340 The antimutagenicity rate and ability of these samples towards extracts from roasted fish

341 skins (50 $\mu \mathrm{g} /$ plate) were limonene: $24-35 \%$; cold pressed lemon oil: $14-24 \%$; and steam

342 distilled extracted lemon essential oil: $15-20 \%$. When compared with high concentrations

343 of fish skin extracts $(200 \mu \mathrm{g} /$ plate $)$, the antimutagenicity rates of the three samples

344 increased by $12 \%, 2 \%$, and $4 \%$ for limonene, cold pressed lemon oil, and steam distilled

345 extracted lemon essential oil, respectively (data not shown).

$347 \quad 3.5$ Toxicity and mutagenicity tests before roasting

Table 2 shows the toxicity of extracts from fish skins after pre-treatment with citrus

349

essential oils and roasting. As the concentration the extract increased, the colony counts

350

showed a decreasing trend. No toxicity occurred when a dose of $150 \mu \mathrm{g} / \mathrm{plate}$ was used

351

regardless of whether liver enzymes were added.

352

The most suitable concentration for toxicity testing, $150 \mu \mathrm{g} / \mathrm{plate}$, was used for

353

antimutagenic ability comparison for various groups. The results are shown in Table 4.

354 Limonene pre-treatment before roasting showed only a slight reduction in mutagenicity

355 when liver enzymes were added. However, similar results were not obtained after liver enzymes were added. We speculate that limonene pre-treatment followed by roasting may 
357 not have effectively inhibited mutagenic substances activated by liver metabolism. In

358 addition, neither cold pressed lemon oil nor steam distilled essential oil was able to reduce

359 the mutagenicity in the roasted fish skins.

360

3613.6 Toxicity and mutagenicity tests after roasting

362

Table 4 shows the toxicity of extracts from fish skins that were treated with citrus

363

essential oils after roasting. As the concentration of the extract increased, the colony

364

counts showed a decreasing trend. Regardless of whether liver enzymes were added, no

365

toxicity occurred when a dose of $150 \mu \mathrm{g} /$ plate was used.

366

The most suitable concentration for toxicity testing, $150 \mu \mathrm{g} / \mathrm{plate}$, was used for

367 antimutagenic ability comparison for various groups. The results are shown in Table 4.

368 Limonene pre-treatment before roasting showed only a slight reduction in mutagenicity

369 regardless of whether liver enzymes were added. Because limonene and other citrus

370 essential oils are volatile substances, high-temperature roasting may dramatically reduce

371 their effective levels, thereby decreasing their antimutagenic abilities. However, treatment

372 with limonene and other volatile substances after roasting does not require high-

373 temperature roasting and thus limonene may be present in the roasted material. This

374 greatly increases the antimutagenic effects of limonene. We hypothesize that the effective 
375 inhibition of mutagenicity by roasting before limonene treatment, with or without

376 addition of liver enzymes, may be attributed the loss of volatile substances during high-

377 temperature roasting, although it doesn't reduce mutagenicity after various treatments, at

378 the same results demonstrate addition of limonene and cold pressure oil will not cause

379 mutagenic risk (Table 4), but lemon essential oils groups (with or without S9 mixture)

380 versus untreated had significantly difference, maybe caused by the evaporation of

381 effective substances during the roasted.

\section{Conclusions}

This study demonstrated that among the four types of citrus essential oils extracted from lemons using different methods, limonene had the highest content of $70 \%$ to more than 90\% [24-28]. This shows that the limonene content in citrus essential oils is extremely high. When standard mutagens were used in antimutagenicity experiments, the antimutagenic abilities of substances in descending order were limonene $>$ cold pressure oil $>$ lemon > grapefruit [29-33]. When extracts from roasted fish skins were used as a mutagen at a concentration of $200 \mu \mathrm{g} /$ plate, the antimutagenicity rate and ability of the

391 three extracts were limonene: $18-23 \%$; cold pressed lemon oil: $18-22 \%$; and steam

392 distilled lemon essential oil: $8-16 \%$. When a concentration of $50 \mu \mathrm{g} / \mathrm{plate}$ of extracts from

393 roasted fish skins was used, the antimutagenicity rate and ability of the three extracts were 394 limonene: 24-35\%; cold pressed lemon oil: 14-24\%; and steam distilled lemon essential 395 oil: $15-20 \%$. In experiments simulating roasting of fish skins, limonene was found to 396 decrease the mutagenicity caused by roasted substances when the three samples were used 
397 for pre-soaking before and after roasting.

398

399 Acknowledgments

400 The research was supported by the Ministry of Science and Technology, R.O.C (MOST)

401 (106-2218-E-022-001) and MOST (107-2221-E-992 -033).

402

403 References

404 [1] Gonzalez-Molina, E, Dominguez-Perles, R, Moreno, DA and Garcia-Viguera, C.

405 Natural bioactive compounds of Citrus limon for food and health. Journal of

406 Pharmaceutical and Biomedical Analysis 2010: 51 (2) 327-345.

407 [2] Oussalah, M, Caillet, S, Salmieri, S, Saucier, L and Lacroix, M. Antimicrobial and 408 antioxidant effects of milk protein-based film containing essential oils for the

409 preservation of whole beef muscle. Journal of Agricultural and Food Chemistry

410 2004: 52(18) 5598-5605.

411 [3] Wróblewska, A, Makuch, E and Piotr M. The studies on the limonene oxidation over the microporous TS-1 catalyst. Catalysis Today 2016: 268 121-129.

413 [4] Issa-Zacharia, A, Kamitani, Y, Tiisekwa, A, Morita, K, and Iwasaki, K. In vitro inactivation of Escherichia coli, Staphylococcus aureus and Salmonella spp. Using 
slightly acidic electrolyzed waster. Journal of Bioscience and Bioengineering 2010:

416 $110308-313$.

417 [5] WHO, (1998). Polynuclear aromatic hydrocarbons. In: Guidelines for drinking-water quality, 2nd ed. Vol. 2. Health criteria and other supporting information. Geneva, World Health Organization. pp. 123- 152.

420

[6] Onwukeme, VI, Obijiofor, OC, Asomugha, RN, and Okafor, FA. Impact of Cooking Methods on the Levels of Polycyclic Aromatic Hydrocarbons (PAHs) in Chicken Meat. IOSR Journal of Environmental Science Toxicology and Food Technology 2015: 9(4) 21-27

[7] Zelinkova, Z, and Wenzl T. The Occurrence of 16 EPA PAHs in Food - A Review. Polycyclic Aromatic Compounds 2015: 35(2-4) 248-284. Muscle Foods: Impact on Composition of Nutrients and Contaminants. Comprehensive Reviews in Food Science and Food Safety, 2018: 17(2) 309-333. amines and polycyclic aromatic hydrocarbons concentrations in meats and breads 
433 [10] Jiang, MH, Yang, L, Zhu L, Piao, JH, and Jiang JG. Comparative GC/MS analysis

434

435

436

437

438

439

440

441

442

443

444

445

446

447

448

449

450

of essential oils extracted by 3 methods from the bud of Citrus aurantium L. var. amara Engl. Journal of Food Science, 2011: 76(9) C1219-25.

[11] Liu, YY, Liu, ZI, Wang, C, Zha, QG, Lu, C, Song, ZQ, Ning, ZG Zhao, S, Lu, XM, and $\mathrm{Lu}$ AP. Study on essential oils from four species of Zhishi with gas chromatography-mass spectrometry. Chemistry Central Journal, 2014: 822.

[12] Ou, MC, Liu, YH, Sun YW, and Chan, CF. The Composition, Antioxidant and Antibacterial Activities of Cold-Pressed and Distilled Essential Oils of Citrus paradisi and Citrus grandis (L.) Osbeck. Evidence-Based Complementary and Alternative Medicine, 2015: Article ID 804091, 9 pages.

[13] Maron, DM., Ames, BN. 1983. Revised methods for the Salmonella mutagenicity test. Mutation Research/Environmental Mutagenesis and Related Subjects, 113(34), 173-215. https://doi.org/10.1016/ 0165-1161 (83)90010-9.

[14] Mortelmans K, Zeiger E. The Ames Salmonella/microsome mutagenicity assay. 2010. Mutation Research - Fundamental and Molecular Mechanisms of Mutagenesis, 2000, 455(1):29-60.

[15] Ghazali, AR, Khairuddin, FM, Nagapan, TS, Basri, DF. 2017. The Mutagenicity and Antimutagenicity of Canarium odontophyllum (Dabai) Acetone Leaves Extracts. 
451 Journal of Agricultural Science. 9(13):62-72.

452 [16] Hsouna, AB,Halima, NB, Smaoui, S, and Hamdi, N. Citrus lemon essential oil:

453 chemical composition, antioxidant and antimicrobial activities with its preservative

454 effect against Listeria monocytogenes inoculated in minced beef meat. Lipids in

$455 \quad$ Health and Disease, 2017: 16146.

456 [17] Bourgou, S, Rahali, FZ, Ourghemmi, I, and Tounsi, MS. Changes of Peel Essential

457 Oil Composition of Four Tunisian Citrus during Fruit Maturation. The Scientific

$458 \quad$ World Journal, 2012: Article ID 528593, 10 pages

459 [18] Navarra, M, Mannucci,C,Delbò, M and Calapai, G. Citrus bergamia essential oil:

460 from basic research to clinical application. Frontiers in Pharmacology, 2015: 6 (36)

$461 \quad 1-7$

462 [19] Vaio, CD, Graziani, G, Gaspari, A, Scaglione, G, Nocerino, S, Ritieni, A. 2010.

463 Essential oils content and antioxidant properties of peel ethanol extract in 18 lemon

464 cultivars. Scientia Horticulturae, 126:50-55.

465 [20] Bacanlı, M, Başaran, AA, Başaran, N. 2015. The antioxidant and antigenotoxic.

466 properties of citrus phenolics limonene and naringin. Food and Chemical Toxicology,

$467 \quad 81: 160-170$.

468 [21] Othman, SNAM, Hassan, MA, Nahar, L, Basar, N, Jamil, S, Sarker, SD. 2016. 
Essential Oils from the Malaysian Citrus (Rutaceae) Medicinal Plants. Medicines.

470 3(13) doi:10.3390/medicines3020013.

471 [22] Stogiannidis, E, Laane, R. 2015. Reviews of Environmental Contamination and

472 Toxicology. 234, doi:10.1007/978-3-319-10638-0_2.

473 [23] Dugo,P, Mondello,L, Dugo, Laura, Stancanelli, R, Dugo, G.2000. LC-MS for the identification of oxygen heterocyclic compounds in citrus essential oils. Journal of. Pharmaceutical and Biomedical Analysis, 24:147-154.

476

477

[24] Högnadóttir A, Rouseff RL. 2003. Identification of aroma active compounds in. orange essence oil using gas chromatography-olfactometry and gas

[25] Wang, Y, Yi, L, Liang, Y, Li, H, Yuan, D, Gao, H, Zeng, M. 2008. Comparative chromatography-mass spectrometry. J Chromatogr A.998:201-211.

481 analysis of essential oil components in Pericarpium Citri Reticulatae Viride and Pericarpium Citri Reticulatae by GC-MS combined with chemometric resolution method. J Pharm Biomed Anal, 46: 66-74.

[26] Park, IK, Kim, JN, Lee, YS, Lee, SG, Ahn, YJ, Shin, SC. 2008. Toxicity of plant essential oils and their components against Lycoriella ingenua (Diptera: Sciaridae). J Econ Entomol. 101:139-44. 
characterization of volatile components of the Japanese sour citrus fruit Citrus nagato-yuzukichi Tanaka. Biosci Biotechnol Biochem. 72:1965-1968.

489 [28] Yu, L, Li, X, Liu, S, Xu, G, Liang, Y. 2009. Comparative analysis of volatile constituents in Citrus reticulata Blanco using GC-MS and alternative moving window factor analysis. J Sep Sci. 32: 3457-65. doi: 10.1002/jssc. 200900267.

492

[29] Venturini, N, Curk, F, Desjobert, JM, Karp, D, Costa, J, Paolini, J. 2010.

[30] Araújo, CP Jr, da Camara, CA, Neves, IA, Ribeiro, Nde C, Gomes, CA, de Moraes, Chemotaxonomic investigations of peel and petitgrain essential oils from 17 citron cultivars. Chem Biodivers. 2010. 7:736-51. doi: 10.1002/cbdv.200900028. MM, Botelho, Pde S. 2010. Acaricidal activity against Tetranychus urticae and chemical composition of peel essential oils of three Citrus species cultivated in NE

$$
\text { Brazil. Nat Prod Commun. 5: 471-6. }
$$
Identification and quantification of the antimicrobial components of a citrus essential oil vapor. Nat Prod Commun. 7:103-107.

[32] Ellouze, I, Abderrabba, M, Sabaou, N, Mathieu, F, Lebrihi, A, Bouajila, J. 2012. Season's variation impact on Citrus aurantium leaves essential oil: chemical composition and biological activities. J Food Sci. 77:173-180. doi: 10.1111/j.1750- 
$505 \quad 3841.2012 .02846 . x$.

506 [33] Wang, J, Chen, HP, Liu, YP, Wei, Z, Liu, R, Fan, DQ. 2013. Deconvolution of

507 overlapped peaks in total ion chromatogram of essential oil from citri reticulatae

508 pericarpium viride by automated mass spectral deconvolution \& identification

509 system. Zhongguo Zhong Yao Za Zhi. 38:1564-1569. 
Table 1. Volatile compound compositions of citrus essential oil extracted by different methods

\begin{tabular}{|c|c|c|c|c|c|}
\hline \multirow{2}{*}{$\begin{array}{c}\text { Retation } \\
\text { time } \\
\text { (min) }\end{array}$} & \multirow{2}{*}{ Compound } & \multirow{2}{*}{$\begin{array}{c}\text { Cold pressed oil (\%) } \\
\text { Lemon }\end{array}$} & \multicolumn{3}{|c|}{ Steam distilled oil (\%) } \\
\hline & & & Lemon & Valencia & Grapefruit \\
\hline 4.95 & $\alpha$ - Thujene & - & 0.50 & - & - \\
\hline 5.10 & $\alpha$ - Pipene & 2.96 & 2.04 & 1.06 & 0.87 \\
\hline 5.91 & Sabinene & 1.17 & 1.30 & 0.52 & 0.75 \\
\hline 6.01 & $\beta$ - Pipene & 13.32 & 6.54 & - & - \\
\hline 6.22 & Myrcene & 1.51 & 2.30 & 3.23 & 2.94 \\
\hline 6.50 & Octyl aldehyde & - & - & 0.25 & 0.78 \\
\hline 6.74 & $\delta$ - Carene & - & - & 0.21 & - \\
\hline 6.87 & $\alpha$ - Terpinene & - & 0.23 & - & - \\
\hline 7.19 & Limonene & 72.68 & 74.66 & 92.96 & 92.39 \\
\hline 7.90 & $\gamma$ - Terpinene & 5.34 & 7.48 & - & - \\
\hline 8.67 & $\alpha$ - Terpinolene & - & 0.41 & 0.52 & \\
\hline 11.76 & Decanal & - & - & 0.32 & 0.44 \\
\hline 12.80 & Citral & - & 0.78 & - & - \\
\hline 13.57 & Geranial & 0.55 & 0.96 & - & - \\
\hline 14.92 & Neryl acetate & - & 0.39 & - & - \\
\hline 15.11 & $\alpha$ - Copaene & - & - & - & 0.32 \\
\hline 15.12 & Geranyl acetate & - & 0.21 & - & \\
\hline 15.25 & $\beta$ - Cubebene & - & 0.22 & - & 0.15 \\
\hline 15.56 & $\beta$ - Caryophyllene & - & 0.40 & - & 0.39 \\
\hline 15.84 & Cycloundecatriene & - & - & - & 0.07 \\
\hline 16.04 & Germacrene & - & - & - & 0.25 \\
\hline 16.13 & Valencene & - & - & 0.33 & \\
\hline 16.16 & Calarene & - & - & - & 0.08 \\
\hline 16.19 & $\beta$ - Bisabolene & 0.22 & 0.57 & - & \\
\hline 16.32 & $\delta$ - Cadinene & - & - & - & 0.29 \\
\hline
\end{tabular}


Table 2. Toxicity and mutagenicity of essential oil from citrus and the extract from grilled fish skin regarding S. typhimurium TA100 with and without S9 mixture (N=3/Group)

\begin{tabular}{|c|c|c|c|c|c|c|c|c|}
\hline \multirow[b]{2}{*}{$\begin{array}{l}\text { Amount } \\
(\mu g / \text { plate })\end{array}$} & \multicolumn{4}{|c|}{ Colony number } & \multicolumn{4}{|c|}{ Number of $\mathrm{His}^{+}$revertant colonies } \\
\hline & Limonene & $\begin{array}{c}\text { Cold pressed } \\
\text { oil }\end{array}$ & $\begin{array}{c}\text { Lemon } \\
\text { essential } \\
\text { oils }\end{array}$ & $\begin{array}{c}\text { Extract from } \\
\text { roasted fish skin }\end{array}$ & Limonene & $\begin{array}{c}\text { Cold pressed } \\
\text { oil }\end{array}$ & $\begin{array}{c}\text { Lemon } \\
\text { essential oils }\end{array}$ & Grilled fish skin \\
\hline \multicolumn{9}{|c|}{ Without S9 mixture } \\
\hline Control & $250 \pm 12$ & $246 \pm 9$ & $210 \pm 16$ & $237 \pm 21$ & $162 \pm 31$ & $206 \pm 10$ & $139 \pm 16$ & $152 \pm 36$ \\
\hline 100 & $200 \pm 45$ & $201 \pm 20^{\#}$ & $188 \pm 23$ & $207 \pm 14$ & $155 \pm 16$ & $153 \pm 28^{\#}$ & $133 \pm 6$ & $588 \pm 38^{\#}$ \\
\hline 200 & NT*\# & $197 \pm 16^{\#}$ & $173 \pm 16$ & $195 \pm 27$ & NT*\# & $172 \pm 16$ & $131 \pm 16$ & $990 \pm 70^{\#}$ \\
\hline \multicolumn{9}{|c|}{ With S9 mixture } \\
\hline Control & $321 \pm 13$ & $300 \pm 22$ & $248 \pm 15$ & $254 \pm 10$ & $211 \pm 17$ & $250 \pm 13$ & $189 \pm 15$ & $197 \pm 23$ \\
\hline 100 & $262 \pm 18^{\#}$ & $250 \pm 15^{\#}$ & $210 \pm 14$ & $243 \pm 5$ & $199 \pm 14$ & $238 \pm 16$ & $165 \pm 21$ & $640 \pm 50^{\#}$ \\
\hline 200 & NT* & $239 \pm 19^{\#}$ & $201 \pm 15$ & $206 \pm 10^{\#}$ & NT*\# & $244 \pm 27$ & $168 \pm 14$ & $1231 \pm 56^{\#}$ \\
\hline
\end{tabular}

*NT: Not tested

$\# \mathbf{p}<0.05$ versus control 
Table 3. Antimutagenic effects and toxicity of limonene and lemon essential oil mixed with the extract from grilled fish skin (200 $\mu g /$ plate) regarding $S$. typhimurium $\mathrm{TA100}$ (N=3/Group)

\begin{tabular}{|c|c|c|c|c|c|c|c|c|}
\hline \multirow[b]{3}{*}{ Amount ( $\mu \mathrm{g} / \mathrm{plate})$} & \multirow{2}{*}{\multicolumn{3}{|c|}{$\frac{\text { Number of } \text { His }^{+} \text {revertant colonies }}{\text { Without } \mathrm{S9} \text { mixture }}$}} & \multirow[b]{3}{*}{ Amount ( $\mu \mathrm{g} /$ plate) } & \multicolumn{4}{|c|}{ Colony number } \\
\hline & & & & & \multicolumn{4}{|c|}{ Without S9 mixture } \\
\hline & Limonene & Cold pressed oil & $\begin{array}{c}\text { Lemon } \\
\text { essential } \\
\text { oils }\end{array}$ & & Tween 20 & Limonene & $\begin{array}{c}\text { Cold } \\
\text { pressed } \\
\text { oil }\end{array}$ & $\begin{array}{c}\text { Lemon } \\
\text { essential } \\
\text { oils }\end{array}$ \\
\hline Control & $776 \pm 30$ & $899 \pm 41$ & $997 \pm 83$ & Control & $174 \pm 33 *$ & $128 \pm 14$ & $154 \pm 34$ & $120 \pm 23$ \\
\hline 100 & $672 \pm 34^{\#}$ & $784 \pm 30^{\#}$ & $949 \pm 97$ & 100 & $146 \pm 24$ & $106 \pm 13$ & $130 \pm 15$ & $101 \pm 15$ \\
\hline 200 & NT*\# & $760 \pm 14^{\#}$ & $907 \pm 36$ & 150 & $142 \pm 16$ & $101 \pm 11^{\#}$ & $122 \pm 22$ & $97 \pm 16$ \\
\hline \multicolumn{5}{|c|}{ With S9 mixture } & \multicolumn{4}{|c|}{ With S9 mixture } \\
\hline Control & $944 \pm 49$ & $1013 \pm 44$ & $1296 \pm 32$ & Control & $150 \pm 13$ & $166 \pm 20$ & $222 \pm 16$ & $165 \pm 27$ \\
\hline 100 & $831 \pm 77^{\#}$ & $931 \pm 49$ & $1317 \pm 24$ & 100 & $205 \pm 19^{\#}$ & $140 \pm 16$ & $184 \pm 22$ & $134 \pm 19$ \\
\hline 200 & $\mathbf{N T}^{\#}$ & $888 \pm 66^{\#}$ & $1224 \pm 24$ & 150 & $193 \pm 17^{\#}$ & $135 \pm 15$ & $175 \pm 19^{\#}$ & $132 \pm 13$ \\
\hline
\end{tabular}

*NT: Not tested

$\# \mathbf{p}<\mathbf{0 . 0 5}$ versus control

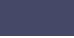

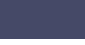

(1) 
Table 4. Mutagenicity of the same extract from grilled fish skin after immersion in limonene and lemon essential oil regarding S. typhimurium TA100 (N=3/Group)

Number of $\mathrm{His}^{+}$revertant colonies

Concentration $(150 \mu \mathrm{g} / \mathrm{plate})$ Different samples

\begin{tabular}{ccc}
\cline { 2 - 3 } Control & Without S9 mixture & With S9 mixture \\
Untreated & $185 \pm 34^{\dagger}$ & $231 \pm 41^{\dagger}$ \\
Tween 20 & $997 \pm 30^{\#}$ & $985 \pm 58^{\#}$ \\
Limonene & $909 \pm 56^{\#}$ & $961 \pm 40^{\#}$ \\
Cold pressed oil & $949 \pm 57^{\#}$ & $1040 \pm 41^{\#}$ \\
Lemon essential oils & $1015 \pm 77^{\#}$ & $1119 \pm 68^{\# \dagger}$ \\
\hline
\end{tabular}

*NT: Not tested

${ }^{\#} \mathbf{p}<0.05$ versus control

${ }^{\dagger} \mathbf{p}<0.05$ versus untreated 